\title{
Present-Day Lake Level Variation from Envisat Altimetry over the Northeastern Qinghai-Tibetan Plateau: Links with Precipitation and Temperature
}

\author{
Hyongki Lee, ${ }^{1, *}$, C. K. Shum ${ }^{1}$, Kuo-Hsin Tseng ${ }^{1}$, Jun-Yi Guo ${ }^{1}$, and Chung-Yen Kuo ${ }^{2}$ \\ ${ }^{1}$ Division of Geodetic Science, School of Earth Sciences, The Ohio State University, Columbus, Ohio, USA \\ ${ }^{2}$ Department of Geomatics, National Cheng-Kung University, Tainan, Taiwan
}

Received 8 April 2010, accepted 9 August 2010

\begin{abstract}
Lakes in permafrost regions are highly sensitive to changes in air temperature, snowmelt, and soil frost. In particular, the Qinghai-Tibetan Plateau (QTP) is one of the most sensitive regions in the world influenced by global climate change. In this study, we use retracked Enivsat radar altimeter measurements to generate water level change time series over Lake Qinghai and Lake Ngoring in the northeastern QTP and examine their relationships with precipitation and temperature changes. The response of water levels in Lake Qinghai and Lake Ngoring is positive with regards to precipitation amount. There is a negative relationship between water level and temperature change. These findings further the idea that the arid and high-elevation lakes in the northeastern QTP are highly sensitive to climate variations. Water level increases in Lake Qinghai in winter may indicate inputs of subsurface water associated with freeze-thaw cycles in the seasonally frozen ground and the active layer.
\end{abstract}

Key words: Qinghai-Tibetan Plateau, Lake water level, Climate variations

Citation: Lee, H., C. K. Shum, K. H. Tseng, J. Y. Guo, and C. Y. Kuo, 2011: Present-day lake level variation from Envisat altimetry over the northeastern Qinghai-Tibetan Plateau: Links with precipitation and temperature. Terr. Atmos. Ocean. Sci., 22, 169-175, doi: 10.3319/TAO.2010.08.09.01(TibXS)

\section{INTRODUCTION}

The Qinghai-Tibetan Plateau (hereafter, QTP), the highest plateau in the world, has an average elevation of more than $4000 \mathrm{~m}$ above sea level, and the permafrost over the QTP occupies about $1.5 \times 10^{6} \mathrm{~km}^{2}$, or approximately $70 \%$ of the permafrost regions in China (Oelke and Zhang 2007). It has been known that lakes in permafrost regions are highly sensitive to changes in air temperature, snowmelt, and soil frost (Gibson et al. 2006; Liu et al. 2009). There have been several studies concerning the interaction between the lake and climate variation in QTP (e.g., Liu et al. 2009; Yu and Shen 2010). In particular, the northeastern QTP has been of interest because it is one of the most sensitive regions to global climate changes, influenced by different monsoon systems (the East Asian summer monsoon, Indian summer monsoon, East Asian winter moon, and westerly jet streams) (Xu et al. 2007).

Satellite radar altimetry has been used to study water elevation changes over lakes (Morris and Gill 1994; Birkett 1995; Lee et al. 2010), rivers (Birkett 1998; Birkett et al.

\footnotetext{
* Corresponding author

E-mail:lee.2444@osu.edu
}

2002; Kouraev et al. 2004; Berry et al. 2005), and wetlands (Kim et al. 2009; Lee et al. 2009). Hwang et al. (2005) generated decadal water level time series using TOPEX/Poseidon (T/P) altimeter data over six inland lakes in China and investigated their links to precipitation and El Niño Southern Oscillation (ENSO).

In this study, we use retracked Environmental Satellite (Envisat) altimeter measurements to generate water level change time series over Lake Qinghai and Lake Ngoring in the northeastern QTP (Fig. 1) and examine their relationships with regard to precipitation and temperature observed by satellites. We do not use T/P data because there is no T/P pass over Lake Qinghai. Lake Qinghai is the largest closed-basin lake in China located in the arid-semiarid area of $3194 \mathrm{~m}$ above sea level. It has an average depth of $21 \mathrm{~m}$ and a lake area of $4260 \mathrm{~km}^{2}$. There are more than 40 rivers flowing into Lake Qinghai, and the total water input is approximately $46 \%$ surface runoff, $42 \%$ direct precipitation, and 12\% local inflow (Yu and Shen 2010). Lake Ngoring is located at the upper reaches of the Yellow River. The lake has an elevation of $4272 \mathrm{~m}$ above sea level, an area of $610 \mathrm{~km}^{2}$ and an average depth of $17.6 \mathrm{~m}$. 


\section{DATA AND METHODS}

In this study, we use retracked Envisat $18-\mathrm{Hz}$ data ( $\sim 350 \mathrm{~m}$ along-track sampling), which spans September 2002 to April 2009 (cycles 10 - 77), from the Geophysical Data Record (GDR) to measure water height changes over the lakes defined by water masks. The water masks we used are from the Shuttle Radar Topography Mission Water Body Dataset (SWBD, http://www2.jpl.nasa.gov/srtm/ index.html) which is a by-product of the data editing to produce the finished SRTM Digital Terrain Elevation Data (DTED) Level 2.

We carefully select $18-\mathrm{Hz}$ measurements obtained from the lake surface after considering the size of the radar footprint and other criteria [for details, see Lee et al. (2010)]. Along each Envisat $18-\mathrm{Hz}$ ground track location, we intersect a circle with an area equivalent to the nominal Envisat footprint size ( $2.5 \mathrm{~km}$ in diameter) with the lake mask to choose each $18-\mathrm{Hz}$ Envisat measurement that is entirely over water (Fig. 2). Water height at a given time is obtained from an average of Envisat measurements for a given pass that fall within the lake. It should be noted that the presence of snow and ice on the lake surface, which may persist for a significant fraction of the year, perturbs the altimeter measurements by volume scattering of the media and two-way attenuation of the radar signal (Papa et al. 2002; Kouraev et al. 2004). The Envisat GDRs contain retracked range measurements using four different retracking algorithms. They are Ocean (Brown 1977), ICE-1 (Bamber 1994), ICE-2 (Legresy et al. 2005), and SEAICE (Laxon 1994).

Due to the lack of or inaccessibility to in situ gauge data over the Lake Qinghai and Lake Ngoring, we perform indirect verification by comparing the Envisat-derived lake levels and in situ gauge records for Lake Athabasca in Canada to choose the best retracker for the lake surface covered by ice and snow. Figure 3 shows the comparison of Envisat-derived lake levels from four different retrackers and in situ gauge measurements in Lake Athabasca near Crackingstone Point (http://scitech.pyr.ec.gc.ca/waterweb/ formnav.asp). Obvious differences among the retrackers can be observed from the lake levels during winter seasons. Table 1, which summarizes correlation coefficients and root-mean-squared (RMS) differences between the Envisatderived and in situ water level anomalies, shows that the

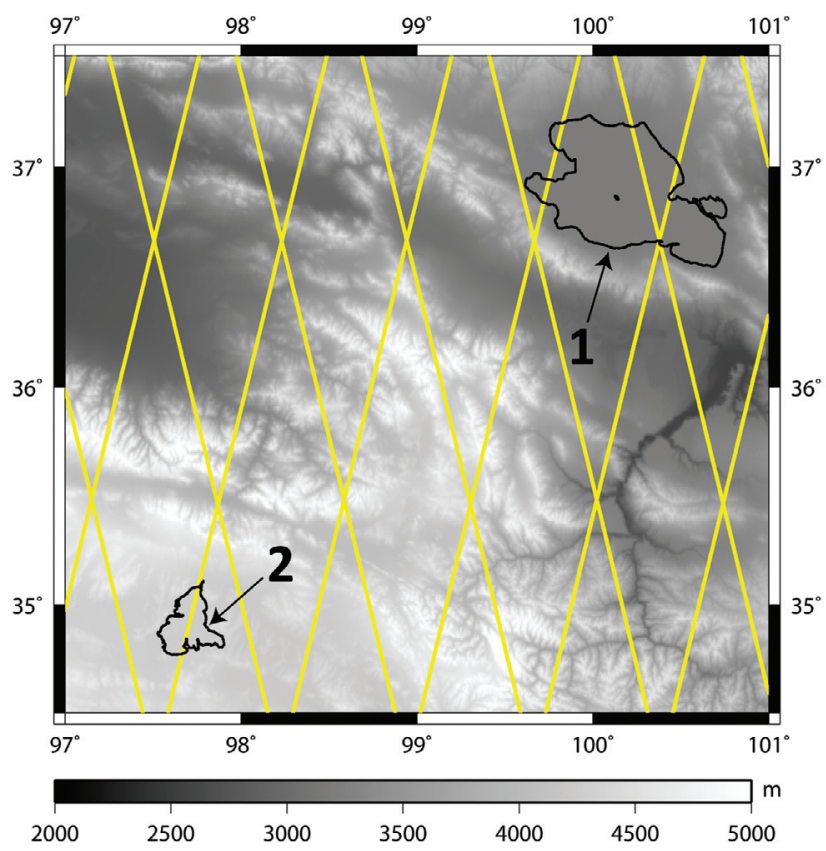

Fig. 1. Locations of Lake Qinghai (1) and Lake Ngoring (2) over the northeastern QTP. Yellow lines are Envisat ground tracks. Background is 30-arcsec resolution GTOPO30 global Digital Elevation Model (DEM).
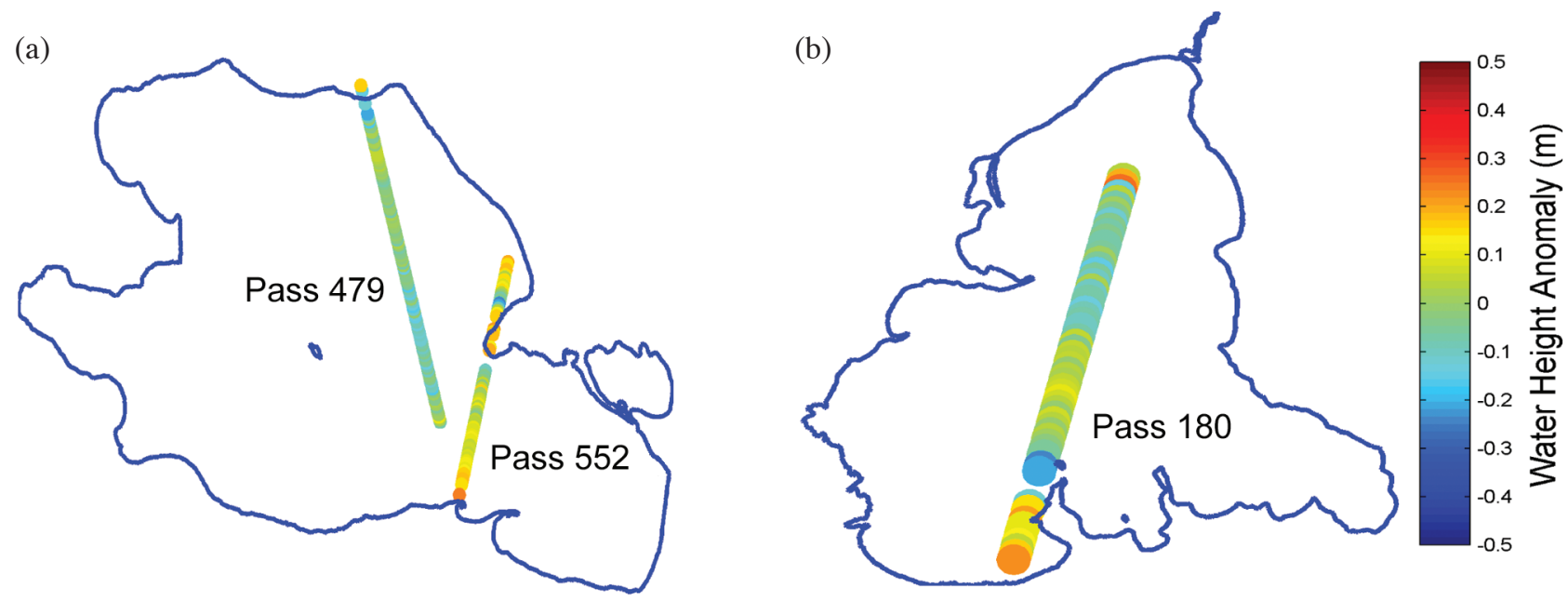

Fig. 2. Envisat ground tracks over Lake Qinghai (a) and Lake Ngoring (b) with color-coded circles representing ellipsoidal height from cycle 41. The water height anomaly is calculated by subtracting the mean value. The size of the circles corresponds to the size of the Envisat nominal footprint. The lake boundary is from SWBD. 

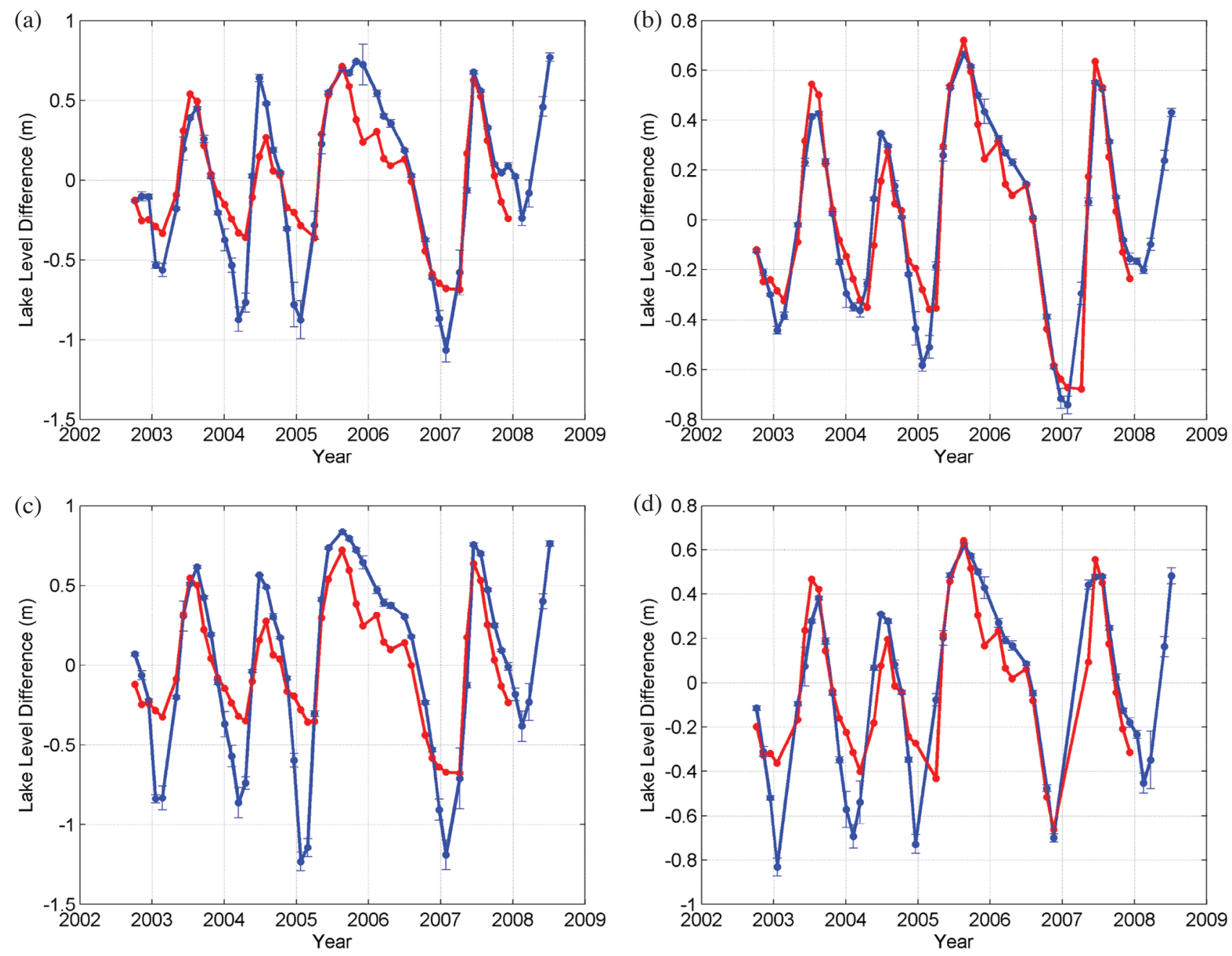

Fig. 3. Comparison of Envisat water level changes from pass 140 (blue) using (a) OCEAN, (b) ICE-1, (c) ICE-2, (d) SEAICE retrackers and in situ gauge records (red) over Lake Athabasca in Canada.

Table 1. Correlation coefficients (CC) and RMS differences between the Envisat-derived (using pass 140) and in situ lake level records over Lake Athabasca in Canada.

\begin{tabular}{l|cc}
\hline & CC & RMS Difference (cm) \\
\hline OCEAN & 0.89 & 24.37 \\
ICE-1 & 0.95 & 11.84 \\
ICE-2 & 0.89 & 30.74 \\
SEAICE & 0.88 & 18.61 \\
\hline
\end{tabular}

ICE-1 retracker, a 25\% threshold retracker (Davis 1997) using the mean power of the waveform calculated using Offset Center of Gravity (OCOG) (Bamber 1994) retracking algorithm (Frappart et al. 2006), is the optimal one for the seasonally frozen lake surface among the four retrackers used in Envisat GDR. Because the lengths of intersection between the altimeter track and the lake are comparable among these lakes, our result should be independent on the lake size.

In addition, media corrections [dry troposphere correction, wet troposphere correction calculated by the French Meteorological Office (FMO) from the European Centre for Medium-Range Weather Forecasts (ECMWF) model, and the ionosphere correction based on Global Ionosphere Maps (GIM)] and geophysical corrections (solid Earth and pole tides) have been applied to the Envisat measurements. The $5.6 \mathrm{~m}$ level Ultra Stable Oscillator (USO) anomalies for Envisat cycles 44 - 77 are corrected using the European Space Agency's (ESA) correction tables (J. Benveniste 2007, personal communications).

For precipitation, we use Tropical Rainfall Measuring Mission (TRMM) 3B43 monthly product which has $0.25^{\circ}$ resolution. To generate rainfall anomalies, we cumulatively sum the TRMM rainfall values and subtract a best-fit linear trend from the integrated sum. For temperature, we use the Moderate Resolution Imaging Spectroradiometer (MODIS) 
8-day land surface temperature product (MOD11C2) which has $0.05^{\circ}$ resolution.

\section{RESULTS}

Figure 4 shows the time series of water level variation over Lake Qinghai and Lake Ngoring along with the rainfall time series. Seasonal water level increases are all associated with the increase of precipitation which peaks around August-September over the two lakes. Despite of sporadic data gaps, Lake Ngoring water level time series shows that there are smaller secondary peaks around April, which could be due to seasonal snow/glacier melt in spring. In Lake Qinghai, there are counterintuitive seasonal water level increases around November/December and water level decreases around March/April. This cannot be the altimeter range measurement error because the pattern is not observed over Lake Ngoring, which has similar water depth and much smaller water body than Lake Qinghai. If the level increase in winter is due to the lake recharge by subsurface water, it should be associated with the freeze-thaw cycles of seasonally frozen ground and the active layer (the layer which freezes and thaws every year) (Liu et al. 2009). It is worth noting that the water level in winter has a similar pattern of slope reversing from negative to positive in year 2006. Therefore, although it is unclear at this stage how exactly the freeze-thaw cycles can lead to the water level increase in winter, it can be conjectured that the water being evacuated into the groundwater system during the thawing cycle (Smith et al. 2005) is blocked during the freezing cycle and thus induces a water level increase. This can also explain the abrupt decrease of the water level in spring when the thawing cycle begins.

It has been known that Lake Qinghai has experienced a severe decline in its water level in recent decades. There was a $3.35 \mathrm{~m}$ decline in water level with an average decreasing rate of $8.0 \mathrm{~cm} \mathrm{yr}^{-1}$ between years 1959 and 2000 ( $\mathrm{Li}$ et al. 2007). However, our results indicate that the lake levels decreased until 2004 and then increased steadily with an abrupt jump in year 2005 over both Lake Qinghai and Lake Ngoring. Li et al. (2007) showed that water consumption by human activities had little effect on water level decline. Therefore, the water level increase after 2005 should be related to the climate variation. We further examine the
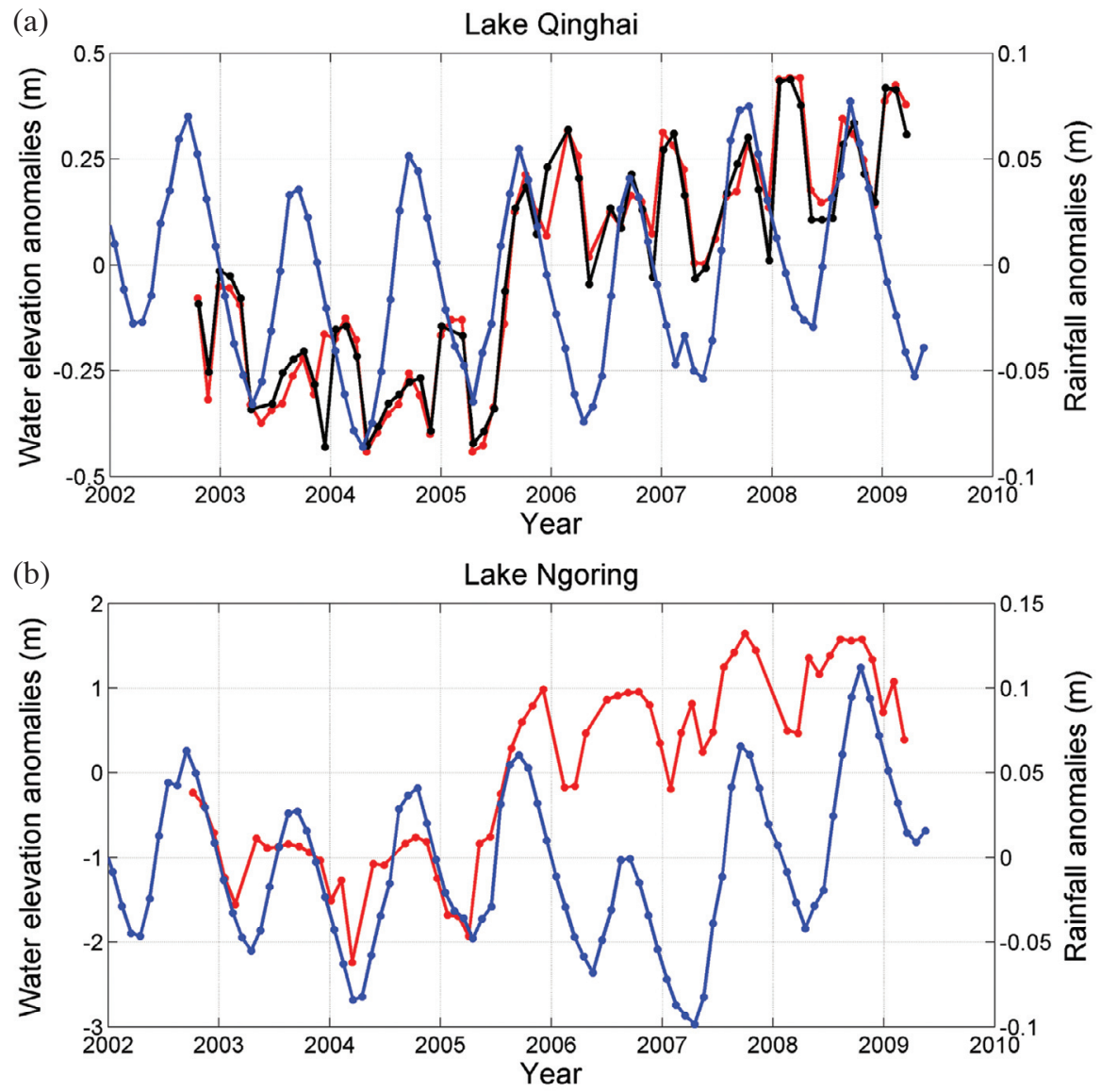

Fig. 4. Lake level anomaly time series (left y-axis) along with TRMM rainfall anomaly time series (right y-axis, blue) over (a) Lake Qinghai (red: Envisat pass 479, black: Envisat pass 552) and (b) Lake Ngoring (red: Envisat pass 180). A close agreement between the time series generated from passes 479 and 552 over Lake Qinghai validates the Envisat measurements. 
precipitation data from TRMM by creating a precipitation anomaly map of September 2005 when the water level and the rainfall reached their peaks in 2005. Figure 5 confirms that there was an excessive positive rainfall anomaly near the lakes, and this should be related to the water increase in 2005 as the precipitation is the major hydrologic input to the basin (along with surface runoff). We also examine the land surface temperature variation from MODIS. Figure 6 shows the time series of temperature variations over Lake Qinghai and Lake Ngoring. It is apparent that the temperature changes with altitude in regions like QTP, and the mean temperature difference between the two lakes is approxi- mately $3.8^{\circ} \mathrm{C}$. It can also be seen that the summer season (June - August) temperatures are gradually decreasing with rates of -0.12 and $-0.31^{\circ} \mathrm{C} \mathrm{yr}^{-1}$ over Lake Qinghai and Lake Ngoring, respectively. It has been known that evaporation is primarily driven by temperature in Lake Qinghai region (Qin and Huang 1998; Li et al. 2007). Hence, the decreasing summer temperature is related to decreasing evaporation, and therefore causing an increase of lake level. This result agrees qualitatively with the simulation study by $\mathrm{Yu}$ and Shen (2010) as they predicted that the water level will increase with the increase of precipitation and will decrease with the increase of temperature over Lake Qinghai.

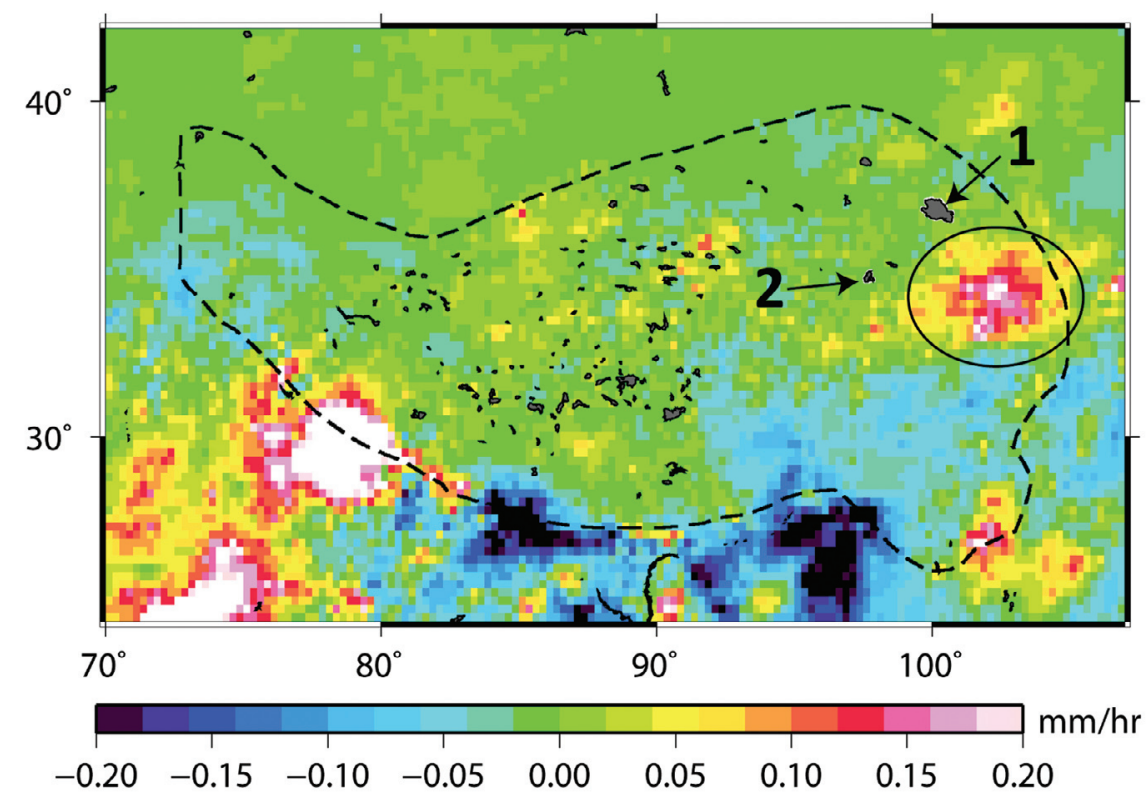

Fig. 5. Precipitation anomaly map for September 2005 with respect to the mean precipitation calculated from each September of 2002, 2003, 2004, 2006, 2007, and 2008. The dashed line shows the approximate boundary of QTP, and the locations of Lake Qinghai and Lake Ngoring are indicated by numbers 1 and 2, respectively. The excessive positive anomaly, indicated with a circle, can be observed near the lakes.

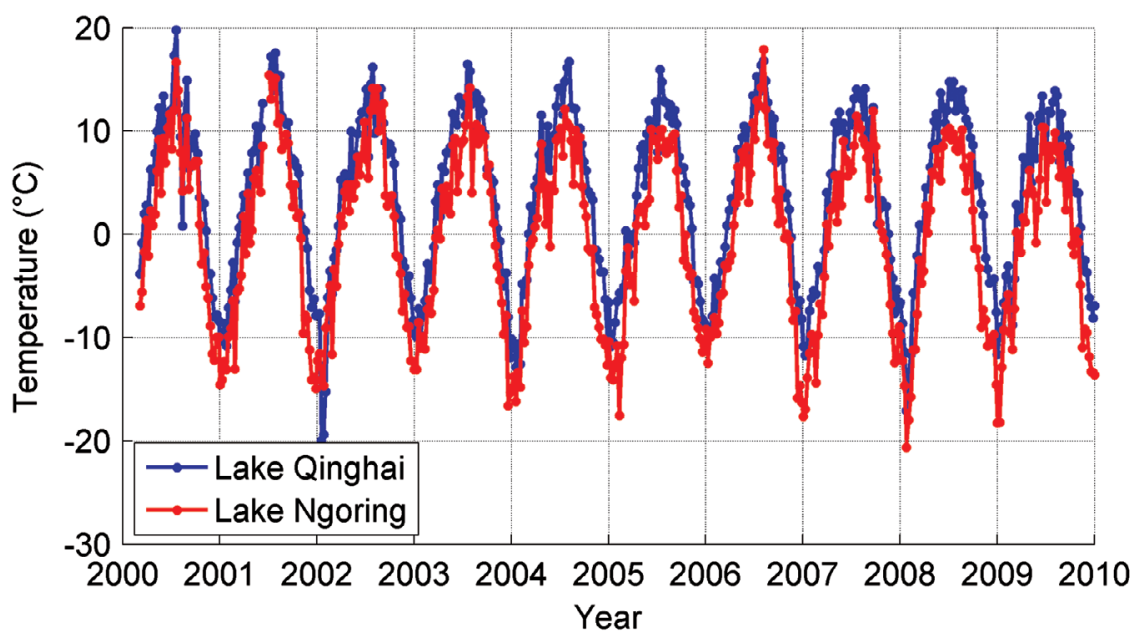

Fig. 6. Land surface temperature time series over Lake Qinghai and Lake Ngoring using MODIS 8-day temporal $0.05^{\circ}$ spatial resolution product (MOD11C2). 


\section{CONCLUSION}

Lake Qinghai and Lake Ngoring, which are approximately $300 \mathrm{~km}$ apart, show similar response to the forcing of two climate variables: precipitation and temperature. Water level increases in the lakes are all associated with the increase of precipitation during August-September and the decrease of temperature. Whether the positive precipitation anomaly is related to abnormal East Asian summer monsoon or Indian summer monsoon is uncertain, and warrants further study. Water level increases in Lake Qinghai in winter should be caused by the subsurface water input which could be related to the freeze-thaw cycles of the active layer below the lake. This is not observed over Lake Ngoring which is located at higher altitude and has lower surface temperature. Future study is needed to examine and validate the subsurface hydrologic cycle using, for example, the Variable Infiltration Capacity (VIC) model which is able to simulate the permafrost process (Cherkauer et al. 2003).

The response of water levels in Lake Qinghai and Lake Ngoring is positive with regards to precipitation amount and negative to temperature change. These findings suggest that the arid and high-elevation lakes in the northeastern QTP are highly sensitive to variations in climate.

Acknowledgements This research is partially supported by grants from the National Geospatial-Intelligence Agency's University Research Initiatives (NURI) Program (HM158207-1-2024), and Ohio State University's Climate, Water, and Carbon Program (http://cwc.osu.edu). We thank anonymous reviewers and the Editor, Cheinway Hwang, for their constructive comments. The SRTM data product used in this study is from NGA via JPL. We acknowledge ESA/ESRIN and NASA/GSFC for providing the Envisat altimetry, and the TRIMM and MODIS data products used in this study.

\section{REFERENCES}

Bamber, J. L., 1994: Ice sheet altimeter processing scheme. Int. J. Remote Sens., 15, 925-938, doi: 10.1080/01431 169408954125. [Link]

Berry, P. A. M., J. D. Garlick, J. A. Freeman, and E. L. Mathers, 2005: Global inland water monitoring from multi-mission altimetry. Geophys. Res. Lett., 32, L16401, doi: 10.1029/2005GL022814. [Link]

Birkett, C. M., 1995: The contribution of TOPEX/POSEIDON to the global monitoring of climatically sensitive lakes. J. Geophys. Res., 100, 25179-25204, doi: 10.1029/95JC02125. [Link]

Birkett, C. M., 1998: Contribution of the TOPEX NASA radar altimeter to the global monitoring of large rivers and wetlands. Water Resour. Res., 34, 1223-1239, doi: 10.1029/98WR00124. [Link]

Birkett, C. M., L. A. K. Mertes, T. Dunne, M. H. Costa, and M. J. Jasinski, 2002: Surface water dynamics in the Amazon Basin: Application of satellite radar altimetry. J. Geophys. Res., 107, 8059, doi: 10.1029/20 01JD000609. [Link]

Brown, G. S., 1977: The average impulse response of a rough surface and its applications. IEEE Trans. Antennas Propag., 25, 67-74, doi: 10.1109/TAP.1977.1141536. [Link]

Cherkauer, K. A., L. C. Bowling, and D. P. Lettenmaier, 2003: Variable infiltration capacity cold land process model updates. Global Planet. Change, 38, 151-159, doi: 10.1016/S0921-8181(03)00025-0. [Link]

Davis, C. H., 1997: A robust threshold retracking algorithm for measuring ice-sheet surface elevation change from satellite radar altimeters. IEEE Trans. Geosci. Remote Sensing, 35, 974-979, doi: 10.1109/36.602540. [Link]

Frappart, F., S. Calmant, M. Cauhopé, F. Seyler, and A. Cazenave, 2006: Preliminary results of ENVISAT RA-2derived water levels validation over the Amazon basin. Remote Sens. Environ., 100, 252-264, doi: 10.1016/j. rse.2005.10.027. [Link]

Gibson, J. J., T. D. Prowse, and D. L. Peters, 2006: Hydroclimatic controls on water balance and water level variability in Great Slave Lake. Hydrol. Process., 20, 4155-4172, doi: 10.1002/hyp.6424. [Link]

Hwang, C., M. F. Peng, J. Ning, J. Luo, and C. H. Sui, 2005: Lake level variations in China from TOPEX/Poseidon altimetry: data quality assessment and links to precipitation and ENSO. Geophys. J. Int., 161, 1-11, doi: 10.1111/j.1365-246X.2005.02518.x. [Link]

Kim, J. W., Z. Lu, H. Lee, C. K. Shum, C. M. Swarzenski, T. W. Doyle, and S. H. Baek, 2009: Integrated analysis of PALSAR/Radarsat-1 InSAR and ENVISAT altimeter data for mapping of absolute water level changes in Louisiana wetlands. Remote Sens. Environ., 113, 2356-2365, doi: 10.1016/j.rse.2009.06.014. [Link]

Kouraev, A. V., E. A. Zakharova, O. Samain, N. M. Mognard, and A. Cazenave, 2004: Ob' river discharge from TOPEX/Poseidon satellite altimetry (1992-2002). Remote Sens. Environ., 93, 238-245, doi: 10.1016/j.rse. 2004.07.007. [Link]

Laxon, S., 1994: Sea ice altimeter processing scheme at the EODC. Int. J. Remote Sens., 15, 915-924, doi: 10. 1080/01431169408954124. [Link]

Lee, H., C. K. Shum, Y. Yi, M. Ibaraki, J. W. Kim, A. Braun, C. Y. Kuo, and Z. Lu, 2009: Louisiana wetland water level monitoring using retracked TOPEX/POSEIDON altimetry. Mar. Geodesy, 32, 284-302, doi: 10.1080/01490410903094767. [Link]

Lee, H., M. Durand, H. C. Jung, D. Alsdorf, C. K. Shum, and Y. Sheng, 2010: Characterization of surface water storage changes in Arctic lakes using simulated SWOT measurements. Int. J. Remote Sens., 31, 3931-3953, doi: 10.1080/01431161.2010.483494. [Link]

Legresy, B., F. Papa, F. Remy, G. Vinay, M. van den Bosch, 
and O.-Z. Zanife, 2005: ENVISAT radar altimeter measurements over continental surfaces and ice caps using the ICE-2 retracking algorithm. Remote Sens. Environ., 95, 150-163, doi: 10.1016/j.rse.2004.11.018. [Link]

Li, X. Y., H. Y. Xu, Y. L. Sun, D. S. Zhang, and Z. P. Yang, 2007: Lake-level change and water balance analysis at Lake Qinghai, West China during recent decades. Water Resour. Manag., 21, 1505-1516, doi: 10.1007/ s11269-006-9096-1. [Link]

Liu, J., S. Wang, S. Yu, D. Yang, and L. Zhang, 2009: Climate warming and growth of high-elevation inland lakes on the Tibetan Plateau. Global Planet. Change, 67, 209217, doi: 10.1016/j.gloplacha.2009.03.010. [Link]

Morris, C. S. and S. K. Gill, 1994: Evaluation of the TOPEX/ POSEIDON altimeter system over the Great Lakes. $J$. Geophys. Res., 99, 24527-24539, doi: 10.1029/94JC0 1642. [Link]

Oelke, C. and T. Zhang, 2007: Modeling the Active-Layer Depth over the Tibetan Plateau. Arct. Antarct. Alp. Res., 39, 714-722.

Papa, F., B. Legresy, N. M. Mognard, E. G. Josberger, and
F. Remy, 2002: Estimating terrestrial snow depth with the TOPEX-Poseidon altimeter and radiometer. IEEE Trans. Geosci. Remote Sensing, 40, 2162-2169, doi: 10.1109/TGRS.2002.802463. [Link]

Qin, B. and Q. Huang, 1998: Evaluation of the climatic change impacts on the inland lake - A case study of Lake Qinghai, China. Clim. Change, 39, 695-714, doi: 10.1023/A:1005319616456. [Link]

Smith, L. C., Y. Sheng, G. M. MacDonald, and L. D. Hinzman, 2005: Disappearing Arctic lakes. Science, 308, 1429-1429, doi: 10.1126/science.1108142. [Link]

Xu, H., Z. H. Hou, L. Ai, and L. C. Tan, 2007: Precipitation at Lake Qinghai, NE Qinghai-Tibet Plateau, and its relation to Asian summer monsoons on decadal/ interdecadal scales during the past 500 years. Palaeogeogr. Palaeoclimatol. Palaeoecol., 254, 541-549, doi: 10.1016/j.palaeo.2007.07.007. [Link]

$\mathrm{Yu}, \mathrm{G}$. and H. Shen, 2010: Lake water changes in response to climate change in northern China: Simulations and uncertainty analysis. Quat. Int., 212, 44-56, doi: 10.1016/ j.quaint.2009.07.020. [Link $]$ 